\title{
CRISIS MANAGEMENT IN SECURITY ENVIRONMENT
}

Public security is, in present-days, the key element of society in national and in international space. The jeopardy of the society obtained unprecedented measure especially after terrorists' threat and attacks. The defence of the society over these threats is ethical and overall human problem. A human being is jeopardized by the ideological or by quasi-humane thoughts and enforced by their power, but also the nature hard acts against him. The interest of governments is to secure the society against the nature disfavour and to secure it also against jeopardised antihuman powers. Risk in human-doing, crisis in technical, technological, economic and social matters are sources of inequality in society. This article is an essay of security research and its aim is to point out to discrepancies in human doing and human being mainly from the viewpoint of crises influence of human and society security.

\section{Basis of security research}

Successful solution of security tasks is not only the question of solving security threats in praxis but it is also a problem of security substance investigation and of respectable tools used for their resolutions. Systematic solution of security matters desires the concentration on theoretical problems related to security, its substance and on specific problems connected with risk, crisis or emergency solutions. The role of the security knowledge is based on detection of security substance, new aspects on security matters, reasons of their origin and methods of their disclosure.

If we intend to perceive the matters of security as a scientific event, we have to clarify the substance of this event and demonstrate that scientific tools for uncover the existence of its substance. Further, to review if this security event exists objectively in specific environment, and if this specific environment influences this security event with its own behaviour and consequences. Objectively it can be said that crystalline environment does not exist and that every space is covert by risk and uncertainty. Risk is the source of danger, fear and distress and crisis is the picture of unbalance.

To discover this unbalance requires finding out the reason why it appears, under what causality, what is its value and significance. According to our opinion, the unbalanced situation is the result of undermined risk and represents the basic point of crisis. To consider the basis of crisis of any entity means to clarify the development life of considered issue and to find out the reasons why a smooth evolution is endangered. Reasons are, apparently, outside as well as inside of the considered matter. The outside reasons in technical and technological elements are characterised as menace (threats), the inside reason lies in loss of reliability. The outside environment is full of risks, the inside of depreciation. Therefore, there are ex facie several ways how to review the unbalanced problem from the view of environment and at the same time from the view of living conditions of the considered feature (element, assets, phenomenon).
Crisis is very difficult but transient phenomenon, peak period to overcome the highest difficulties, peak of tension, determining moment after which the change in the development of the operation (organisation, system) begins. It is a complex of fast developing actions that enlarge the scope of destabilising powers over the acceptable level and enlarging violence in the institution (system). Crisis is a situation where jeopardy of assets, interests or aims of interested entities turns up. Crisis is a moment of risk, danger, fear or uncertainty in value production, industry, business, banking and financing, in the all economy, politics and society.

The American Heritage Dictionary defines the crisis as: 1. a) Crucial or decisive point or situation; a turning point; $b$ ) An unstable condition, as in political, social, or economic affairs, involving an impending abrupt or decisive change. 2. A sudden change in the course of a disease or fever, toward either improvement or deterioration. 3. Emotionally stressful events or traumatic change in a person's life.

According to WordNet the noun crisis has two meanings: 1 . unstable situation of extreme danger or difficulty; 2 . crucial stage or turning point in the course of something.

According to the US Department of Defence Dictionary the meaning of crisis is expressed in this way: "An incident or situation involving a threat to the United States, its territories, citizens, military forces, possessions, or vital interests that develops rapidly and creates a condition of such diplomatic, economic, political, or military importance that commitment of US military forces and resources is contemplated in order to achieve national objectives."

Even any other definitions can be used to characterise the substance of crisis, but there is no need to concentrate further on this subject since we are not dealing basically with crisis as a subject matter. The most important role is in application of these definitions or meanings to the special fields of consideration. To deal with crisis is to role of crisis management.

\footnotetext{
* Ján Mikolaj

Faculty of Special Engineering, University of Žilina, 1. mája 32, SK-010 26 Žilina, Slovakia, E- mail: Jan.Mikolaj@fsi.utc.sk
} 


\section{Crisis management}

Crises Management can be generally considered in two ways:

1) as a common problem related to all project subjects under consideration that deals with formal models and tools of different technologies (e.g. industry, business and operation, transport, finance, etc.), or

2) to go directly to the middle of the solution of the specific problem and from, the feasible crisis management solution tools, choose the right one that can solve the incident crisis situation.

In the first way there is a need to know not only the overall basic problems of the performance of the investigated subjects and their environment (technical, technological, economic, social, etc.), but, on the one hand, also crises elements with which these subjects can be confronted, and, on the other hand, the methods and tools of crises management solutions that can be chosen for feasible solution.

In the second way, simply saying, a specific problem has a specific solution. A partial problem of investigated subject has only specific solution for solving this specific partial problem. In practice it means that specific, say emergency situation, can be solved only by relevant and respected tool that is placed at a disposal. In this sense, the specific partial problem can be solved only by specific measures (e.g. in a traffic accident heavy injured people can be transported only by ambulance), but the problem itself cannot be solved with this tool in complexity (road, railways, airplane traffic accidents, or terrorist attacks on people, objects or on infrastructure, etc.).

There exist even other ways that are going directly to the substance of crisis problem solution. As it was already mentioned, crisis is the specific form of considered matter development and always has the reason for its birth. So to consider the origin of the matter evolution can be the source of crisis genesis. To use a crisis like a method of influence the development is also the aim of so called crisis management. Knowing tools of crisis management that can be used in specific forms in specific environment and to apply them in a right way to decrease tension coming from stress situation is also the crisis solution road but used with relevant tools coming from different space. This enables us to consider the crises management as an overall instrument of crisis solution.

Taking to account that risk is a source of crisis, the problem of risk could be wide spread to the crisis management tasks. The advantage of this solution lies on such merit that the crises management can solve a crisis situation in more broadness and in relation to its substance. Therefore, the bases of crisis management could be considered as an application tool for development of relevant circuits of items. For specific items solutions problems specific tools can be directly chosen in relation to their specific characteristics, attributes and objectives. This is usually how research and in firms, managing institutions, deal with solving their complicated technological and economic task. This can be an attitude to risk and crisis solutions through the application of crisis management in entrepreneurship.

Before considering different sights to crisis management and their use in solving security situations, let us have a look at some definitions that can be found in some of sources or my own interpretation. For being short, we can find this expression of crisis management (quoted only partially):

Crisis management involves identifying crisis, planning a response to the crisis, confrontation and resolving the crisis. Crisis management can be applied in almost any field of endeavour, but it is most commonly used in international crises relations, political sciences, economics and specific managerial cases (environment, infrastructure, etc.). In general terms, the theory of crisis management can be divided into crisis three fields, in bargaining and negotiation, in crisis decision-making and in crisis dynamics.

In business the crises events may be divided in these fields: -) Financial crisis - in short term liquidity or cash flow problems; in long term bankruptcy problems; -) Public relations crisis - negative publicity that could adversely effect the success of the company; -) Strategic crisis - changes in the business environment that call the viability of the company into question, etc.

US Department of Defence Dictionary of Military and Associated Words, 2003 defines the crisis management as "Measure to solve a hostile situation and investigate and prepare a criminal case for prosecution under federal law. Crisis management will include a response to an incident involving a weapon of mass destruction, special improvised explosive device, or a hostage crisis that is beyond the capacity of the lead federal agency." As crisis management is very often identified with military agenda, this quoted military definition can be probably useful for the researcher even if this task is not within the framework goals that are being under civil security solutions.

Crisis management on political level is considered as a tool for governmental policy in securing the inner security against the outboard danger, or as a tool for defence of state interests in political and social manners. Crisis management can be also considered as a basic strategic concept in the state (governmental) security policy that contributes to the efficient defence against national and international significant crises situations and conflicts.

Crisis management can be considered as a matter of security either as technological security defined as reliability, or as firm (entrepreneur) security defined as capital, financial, labour, legal et al. In the entrepreneurial (business, enterprise) activities crisis management is known as a method of guidance (control, operation, supervision) and than as a rectification (regulation) or entrepreneurship activities in such way that if any crisis arises and if crisis occurs, the restructure of the firm will be possible but always on higher level of operation what presents an acceleration element. If this will not succeed the entrepreneur activities may vanish. 
Crisis management can be considered as public and social problem embodied in ethnical, ideological, migration, unemployment, education, poverty and other similar problems. In case that these problems are not continually solved they can flow in conflicts on national or even international level.

Generally, crisis management can be then defined as a specific activity of leading personnel concentrated on solving extraordinary and/or critical situation by using specific principles, methods and performance with the aim to overcome its negative consequence (effect). As a result the reason lies on functional recovery of considered entity.

Crisis management is a complex of operation (guidance) activities of supervision (steering) bodies with concentration on risk and nuisance analyses, on applying progressive anti crises remedies, on organisation, realisation and control of activities conducted by building-up actions against occurrence of possible crises situations (i.e. stage of prevention) and of activities on their solutions.

Crisis management as institutional entity (note: does exist in some countries on national, regional and/or local levels) means an organisation of leading and analytical bodies with concentration on analysis of crises events genesis, their possible reasons, consequences and results, choosing methods and remedies on their preventions and on elimination of their outcomes.

Crisis management as theoretical discipline is a logically and methodologically ordered scheme of potential crises, their reasons and consequences, of principles, methods and measures of their solutions.

\section{Security definitions}

If we intend to qualify the security environment, let us have look first at the security expressions.

The term security comes from Latin securitas, $f$. that means insouciance, safety, certainty, safeguard, even peace of mind [1].

The Compact Oxford Dictionary characterises the security term as: 1 . State of being or feeling secure; 2 . Safety of a state or organization against criminal activity such as terrorism or espionage; 3 . Thing deposited or pledged as a guarantee of the fulfilment of an undertaking or the repayment of a loan, to be forfeited in case of default; 4. Certificate attesting credit, the ownership of stocks or bonds, etc.

The American Heritage Dictionary of the English Language, Fourth Edition, 2000 the password security specifies as: 1. Freedom from risk or danger; safety. 2. Freedom from doubt, anxiety, or fear; confidence. 3. Anything that gives or assures safety, as a) a group or department of private guards, b) measures adopted by a government to prevent espionage, sabotage, or attack, c) measure adopted, as by a business or homeowner, to prevent a crime such as burglary or assault, d) measures adopted to prevent escape, ... .
4. Something deposited or given as assurance of fulfilment of an obligation; a pledge. 5. One who undertakes to fulfil the obligation of another; surety. 6. Plural. Written evidence of ownership or creditorship; especially a stock certificate. 7. Measures adopted to guarantee freedom or secrecy of action, communication, of the like, as in wartime.

The Encyclopaedia of Security Management defines the security only in an indirect way. In the password of security system it says that establishing important assets can be attractive aim for several threats. The threats can arise from casual or highly sophisticated actions from very good armed and trained professional criminals, drug users or terrorists. The background of threats is a key to form security systems. From this point of view it can be deduced that the nucleus of security can be understood as personal assault, public nuisance and property and assets.

This understanding can be found by characterising the role of security manager when he expressed that the best defence against dynamic threats and possible catastrophic damages is fully integrated security programme which composes architectonic, technological and operational elements into flexible and sensitive security system.

In the WordNet Lexicon we can find these nine meanings of security: 1 . the state of being free from danger or injury; 2 . a formal declaration that documents a fact of relevance to finance and investment; the holder has a right to receive interest or dividends - synonym: certificate; 3 . a department responsible for the security of the institutions property and workers; 4 . measures taken as a precaution against theft or espionage or sabotage etc.; 5. defence against financial failure - synonym: protection; 6 . freedom from anxiety or fear; 7. an electrical device that sets off an alarm when someone tries to break in - synonym: security system; 8 . property that your creditor can claim in case you default on your obligation synonym: surety; 9 . a guarantee an obligation will be met - synonym: surety.

Very important is the NATO view on the security issue. In the NATO Handbook, [7] we can read this recognition of security: "To provide one of the indispensable foundations for a stable Euro-Atlantic security environment based on the growth of democratic institutions and commitment to the peaceful resolution of disputes, in which no country would be able to intimidate or coerce any other trough the threat or use of force" (page 31-32).

The European Union understands the security, from the viewpoint of common foreign and security policies, as an assurance of security of the Union and its citizens and therefore the minimising of different sources of threads. The security policy determines the scope and means of activities that minimises risks. The background of this policy is incorporated in the security doctrine. The security system incorporates the economy, politics, culture of society and personality, science and technology, geopolitical and geostrategical situation and public activity. 
Bearing in mind all the expression of security one can see that the meaning is very different and indicates the attitude of its observer to security. Anyhow, for the scientific point of view, it is required to express the substance of the security matter as a starting point of scientific methodology that deals with security issues.

\section{Security environment}

For the illustration of security meaning in entrepreneur's environment we can use the characteristic that can be found in the Encyclopaedia of Security Management [3]. The security of a firm lies on: 1 . improvement of quality and prices, 2 . to built up tight relations with consumers, 3 . to create close relations with suppliers, 4. to guarantee effective use of technology, 5. to employ minimal size of levels in managerial hierarchy, 5. systematically improve the qualification of security staff.

Let us try to identify in what environment we can locate the security events. In our contribution to the Conference of Security, Košice 2004, we expected to allocate the security problems primarily in these areas: - security of territory; - defence before unexpected danger and attacks; - armed and militant conflicts; - security (safety) of people and property; - civil security, - security of society; - jeopardy by violence; - jeopardy by mass attacks on inhabitants and on buildings and structures: terrorisms; - frauds, - malversation, defraudation, intimidation; - security (safety) before pseudo philosophic forces; - psychical, moral, ethical, belief, opinion; - security guaranteed by law; - financial, economic, industrial, energetic, infrastructure, commercial, consumer protection security; - technical and technological security, - security of special equipment; - hardware and software security, etc.

Science and technology is also the key to Europe's future. Scientific research, technological development and innovation are at the heart of the knowledge-based economy, a key factor in growth, the competitiveness of companies and employment.

The European Union has recently placed research to the service of security. The reasons are mainly in the security situation not only in European but also mainly in the world-wide security situation. Therefore the European Union puts great emphasis on security research alongside informatics and technology. The European Union therefore considers security as a major challenge in Europe: the security of individuals, the State, transport and telecommunications networks in the face of organised crime and international terrorism, in particular bio terrorism. Increasing security involves advancing knowledge of detection, intelligence, reconnaissance and surveillance, as well as analysis of causes of conflicts.
At the beginning of 2004 a preparatory action on this issue was launched. Taking this a stage further, and on the basis of the report of a high-level European group, a clearly identified "European Security Research Programme" is due to be implemented. With more substantial resources allocated to it, the aims will be to: - increase public security in Europe in the fields of civil protection, for example, and combating bio terrorism; - help the Union to fulfil its tasks of preserving peace, preventing conflicts and strengthening international security, in keeping with the principles of the United Nations Charter. We highlight this above all because the Faculty of Special Engineering of the University of Žilina, and I personally, are working on project proposal within the EU research programs.

Similar situations are with NATO security research [8]. The priority research topics on countering threats to security are in less obviously dangerous fields, but are in areas that nevertheless pose a risk to security and stability, particularly in a regional context, and scientific and technical studies. These priority topics concentrate on: - environmental security (e.g., desertification, land erosion, pollution, etc.), - water resources management, - management of non-renewable resources, - modelling sustainable consumption (e.g., food, energy, materials, fiscal measures and environmental costing), - disaster forecast and prevention, - food security, - information security, - human and societal dynamics (e.g. new challenges for global security, economic impact of terrorist actions, risk assessment, management of science, science policy, security), - related political science, and international relations in general.

As we can see, the security environment is in the focus on human interest. Human life is a central point of human being and it cannot exist if it is jeopardised by nature or by other people due to the lack of human honesty.

\section{Summary}

Security has many faces. In this article we have tried to describe the basis of security events. Due to the last incidents in the world, the security task gains an extraordinary attention. Higher attention is paid to the security research in the programs of international institutions including NATO and European Union. The subjects of research are not only classical security issues but under considerations are new security cases with high influence on society and new technologies, and actions connected with solving extraordinary and emergency situations with which are we endowed by the nature.

\section{References}

[1] ŠPAŇAR, J., HRABOVSKÝ, J.: Latin - Slovak, Slovak - Latin vocabulary, Slovenské pedagogické nakladatelstvo, Bratislava, 1987

[2] The American Heritage Dictionary of the English Language, Fourth Edition, 2000

[3] FAY, J. J.: Encyclopaedia of Security Management, Butterworth-Heinemann, USA, 1993

[4] MIKOLAJ, J.: Security Task (in Slovak), International terminology workshop, Security, Security Risk and Threats in Security Management, University of Žilina, Faculty of Special Engineering, 9. september 2003, proceedings, pp. 56-63 
[5] PAWERA, R.: New View on Security in European Union (in Slovak), Policajná teória a prax, Akadémia policajného zboru, Bratislava, $3 / 2004$

[6] Science and technology, the key to Europe's future - Guidelines for future European Union policy to support research, Commission of the European Communities, Brussels, 16. 6. 2004, COM (2004) 353 final

[7] NATO Office of Information and Press, Brussels, 2001

[8] NATO - Security Trough Science.htm

[9] www.uniba.sk/filit

[10] http://www.answers.com/crisis\%20management. 